\title{
Diel variation of zooplankton distributions in Hawaiian waters favors horizontal diel migration by midwater micronekton
}

\author{
Kelly J. Benoit-Bird ${ }^{1, *}$, Marnie Jo Zirbel ${ }^{1}$, Margaret A. McManus ${ }^{2}$ \\ ${ }^{1}$ College of Oceanic and Atmospheric Sciences, Oregon State University, 104 COAS Admin Bldg., Corvallis, Oregon 97333, USA \\ ${ }^{2}$ Department of Oceanography, University of Hawaii at Manoa, 1000 Pope Road, Honolulu, Hawaii 96822, USA
}

\begin{abstract}
Micronekton in deep-scattering layers around the Hawaiian Islands undergo diel migrations with both vertical and horizontal components. We sought to determine whether resource availability provides an adaptive explanation for this migration. We simultaneously measured the spatio-temporal patterns of micronekton, using acoustics and imaging optics, and of their potential zooplankton prey, using net tows, acoustics, and optics. Zooplankton biomass, density, and total abundance were higher at night than prior to sunset at nearshore sites, whereas relatively little diel variation was observed offshore. All measures of zooplankton availability were 5 to 6 times higher nearshore than offshore during nighttime hours when migrating micronekton species were nearshore. There was no significant nearshore-offshore gradient in zooplankton prior to sunset, leading to 2 possible explanations for the day-night patterns in zooplankton: benthic emergence and vertical migration coupled with horizontal motion. Analysis of taxonomic patterns from net tows did not support the benthic emergence hypothesis. All 3 zooplankton assessment techniques supported the conclusion that zooplankton distribution could favor horizontal migration by micronekton given the pressures for micronketon to be in deep water during daylight to avoid predators. Recently published work has shown that small animals (2 to $10 \mathrm{~cm}$ in length) in scattering layers comprised of micronekton travel distances of at least $11 \mathrm{~km}$ roundtrip each night, often against currents, to obtain these increased food resources. The length and likely cost of the journey provides some insight about the importance of the potential feeding gains.
\end{abstract}

KEY WORDS: Micronekton · Diel migration · Zooplankton · Resource availability · Acoustics · Optics

\section{INTRODUCTION}

Many zooplankton and micronekton undergo diel vertical migrations. Usually these animals reside in deeper waters during the day and ascend into near surface layers at night (Longhurst 1981). The timing and vertical extent of these migrations are affected by light levels (Clarke 1970, Blaxter 1974, Ringelberg 1995), food resources (George 1983), and temperature and other environmental factors (Enright 1977). The widespread occurrence of these movements suggests that the advantages of migration outweigh energetic expenditures and other potential costs.

Diel vertical migration has been hypothesized to result from a balance among the selective pressures of energy acquisition, energy expenditure, and predation risk (see review by Lampert 1989). The vertical irradiance gradient in the ocean results in more photosynthesis and thus more food near the surface, and a greater range of visual detection by predators (Gliwicz 1986). Moving into surface waters to feed only at night while remaining in deep, dark waters during the day allows vertical migrators to maximize survival by minimizing their risk of visual predation while still accessing abundant food resources at the surface (Stich \& Lampert 1981, Ohman et al. 1983, Gliwicz 1986).

Like most deep sound-scattering layers (Roe 1974), the layer of mesopelagic micronekton around the Hawaiian Islands undergoes diel vertical migrations, with an amplitude of up to $600 \mathrm{~m}$ (Reid et al. 1991, Reid 
1994, Benoit-Bird \& Au 2006). Unlike scattering layers that have been extensively studied elsewhere, the diel migration of the mesopelagic layer near Hawaii includes a nearshore-offshore component (Benoit-Bird et al. 2001). This results in micronekton coming within $1 \mathrm{~km}$ of the shoreline at night, into water as shallow as $25 \mathrm{~m}$ and then returning to deeper offshore waters before dawn, a round trip movement of at least $11 \mathrm{~km}$ over the island's slope (Benoit-Bird \& Au 2006). Diel horizontal migrations of micronekton have also been observed in other areas with high bottom relief (Sasaki 1914, Omori \& Ohta 1981, Bordes et al. 1999). However, the mechanisms and cues underlying the diel movement of micronekton capable of significant swimming have received little attention.

The extensive horizontal migrations undertaken by various mesopelagic myctophid fish, shrimp, and squid each day (Benoit-Bird \& Au 2006) suggest that they must provide strong benefits. The animals make these swims actively, often against the prevailing currents (McManus et al. 2008), highlighting the potential though unmeasured energetic costs of this behavior. We hypothesized that horizontal migration provides the micronekton with greater access to food resources. While the gut contents of species from the horizontally migrating layer around Hawaii have not been reported, many similar species of vertically migrating micronektonic animals living father offshore (including those in the same genera as horizontally migrating species) are zooplanktivorous and feed in the upper $250 \mathrm{~m}$ on euphausiids and medium to large copepods (Clarke 1980). A limited number of studies have characterized the composition of the oceanic zooplankton assemblages near the Hawaiian Islands. These include investigations of pelagic gammaridean amphipods (Brusca 1973), copepods (Hirota \& Szyper 1976, Leis 1982, Ferrari \& Hayek 1990, Hassett \& Boehlert 1999), chaetognaths (Szyper et al. 1976, Kimmerer 1984), and mixed zooplankton assemblages (Hirota \& Szyper 1976, Hu 1978). nearshore-offshore gradients in zooplankton abundance have been observed in these waters, paralleling measures of phytoplankton abundance (Leis 1982, Hassett \& Boehlert 1999). These gradients may be a result of the 'island-mass' effect (Doty \& Oguri 1956). An island, by interacting with circulation, can increase biological activity by creating eddies, forming wind and current shadows, shallowing the nutricline, or leaching important nutrients. In addition, nearshore zooplankton abundance appears to be higher at night than during the day (Hassett \& Boehlert 1999), and many of the nocturnal zooplankters belong to taxa that emerge from within or near the seafloor in shallow waters over reefs and flats (Hobson \& Chess 1979). Thus, micronekton migrating into nearshore waters over reefs and flats are likely to encounter a substantially richer forage than is available in the offshore epipelagic.

Our goal was to determine whether food availability provides an adaptive explanation for the nearshore migration of micronekton around the Hawaiian Islands by simultaneously measuring the movements of the mesopelagic layer and the density, abundance, and identity of potential zooplankton prey. Specifically, we tested the prediction that zooplankton biomass and density are higher nearshore than offshore during nighttime hours when migrating micronekton species are feeding.

\section{MATERIALS AND METHODS}

Sampling. Sampling was conducted off the 31 foot (9.5 m) FV 'Alyce C' using shipboard echosounders, a high-resolution vertical profiler, and zooplankton net tows. Underway sampling of transects was conducted at a vessel speed of approximately 5 knots $\left(2.6 \mathrm{~m} \mathrm{~s}^{-1}\right)$. The study area extended west of the leeward coast of Oahu, Hawaii, USA, covering 2 sites: a southern site in the vicinity of $21^{\circ} 19.3^{\prime} \mathrm{N}, 158^{\circ} 8.3^{\prime} \mathrm{W}$ and a northern site surrounding $21^{\circ} 30.5^{\prime} \mathrm{N}, 158^{\circ} 14.2^{\prime} \mathrm{W}$ (Fig. 1).

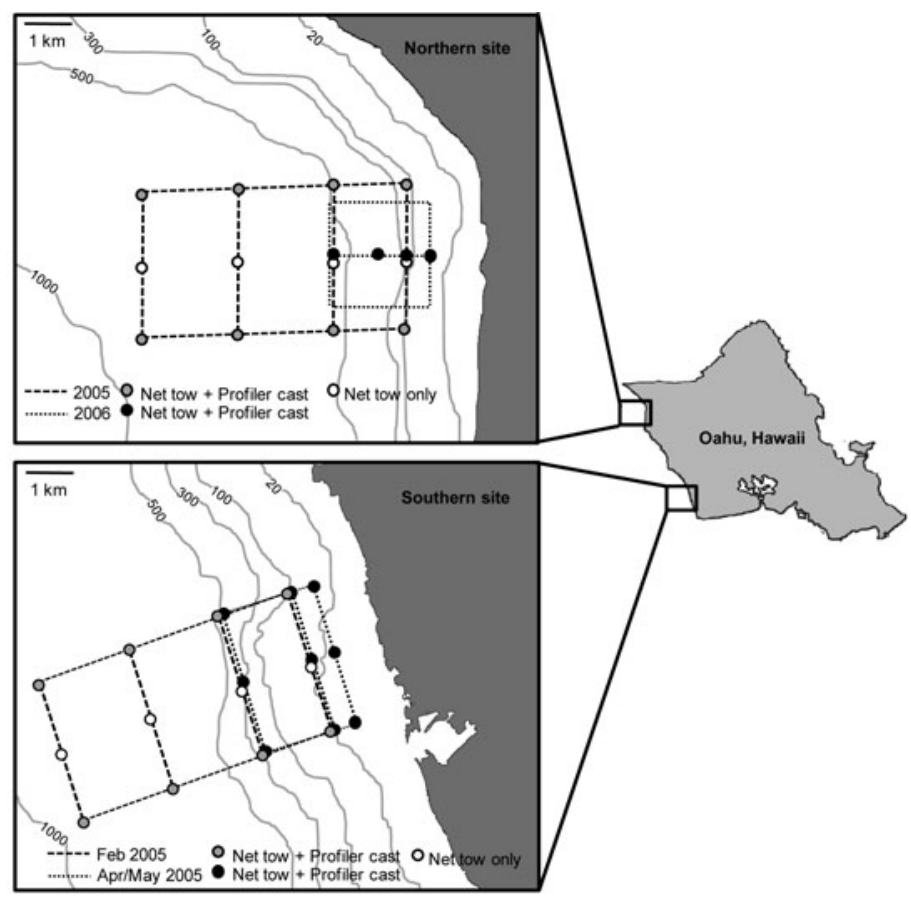

Fig. 1. Transect sampling design at 2 sites off the leeward coast of Oahu, Hawaii. Bottom contours are shown in meters. Both sites were sampled during 2 different cruises, indicated by different dashed patterns. Note the slight offset of transects that were sampled during both cruises for clarity. The position of casts with the vertical profiler and net tows are indicated by circles 
Sampling was conducted between 18:00 and 04:00 h local time from 20 to 28 February 2005. At each site, $3 \mathrm{~km}$ long transects were located at 1.5, 3.0, 5.0, and $7.0 \mathrm{~km}$ from the shoreline. These distances were chosen based on the results of Benoit-Bird \& Au (2006) showing that this range covers nearly the entire nighttime range of the horizontally migrating mesopelagic layer. Over the course of the sampling period, each transect was sampled once in the hour following 18:00, 21:00, 00:00, and 03:00 h local time. The order of sampling by site and the order of transects within a site was determined using a randomized complete block design with only 1 site surveyed in a single night. High resolution profiles were taken at the end of each transect, and vertical net tows for zooplankton were conducted at the ends and midpoint of each transect. Each transect, including all net tows and vertical profile, was completed in less than $1 \mathrm{~h}$. The transect at 18:00 h was completed before sunset, which occurred nominally at 19:00 h throughout the study.

Between 20 April and 27 May 2005, the southern site was sampled from 20:00 until 03:00 h local time during four 3 night series. The surveys coincided with spring (full moon 23-25 April, new moon 7-9 May, full moon 22-24 May) and neap (first quarter 15-17 May) tides. Sampling in each 3 night survey was conducted continuously. Three $3 \mathrm{~km}$ long transects were located 1.0, 1.5 , and $3 \mathrm{~km}$ from the shoreline. Vertical casts with the profiling package and a zooplankton net were carried out at the ends and midpoint of each transect. The starting position along the survey grid was randomized each night, as was the order of the transects.

Between 9 April and 16 May 2006, the northern site was sampled from 20:00 until 03:00 h local time during three 3 night series. The surveys coincided with spring (full moon 13-15 April, new moon 26-28 April) and neap (third quarter 12-14 May) tides. All surveys spanned both ebb and flood of each tidal cycle. Three $3 \mathrm{~km}$ long transects were located across slope, running from 1 to $3 \mathrm{~km}$ from shore. Vertical profiles and net tows were conducted $1,1.5,2$, and $3 \mathrm{~km}$ from shore along the center transect. The position of the first cast with the profiler and net along the center transect was randomly selected each night, as was the initial transect direction toward or away from shore and whether the right or left flanking transect was sampled next.

Data were collected at the southern and northern sites in the springs of 2 different years. Sampling was conducted on 12 nights at the southern site in 2005 and 9 nights at the northern Site in 2006, all in the same month in each case. Because each site was sampled in a different year, inter-site comparisons are not appropriate. The primary purpose for these data was to determine if the patterns observed over 9 contiguous nights in February 2005 were consistent over a longer time period. Other sampling considerations meant that profiles and net tows were not conducted as far from the shoreline. However, at each site, at least the 1.5 and $3.0 \mathrm{~km}$ transects overlapped with those conducted in February 2005.

Echosounders. Along each transect, micronekton scattering was continuously recorded using Simrad EK60 split-beam echosounders at 38, 70, 120, and $200 \mathrm{kHz}$. The $38 \mathrm{kHz}$ system used a pulse length of $1024 \mu$ s and had a $12^{\circ}$ conical beam. The 70,120, and $200 \mathrm{kHz}$ echosounders each had a beam angle of $7^{\circ}$ with pulse lengths of 512, 256, and $256 \mu \mathrm{s}$, respectively. Echosounders were calibrated using an indirect procedure incorporating a $38.1 \mathrm{~mm}$ diameter tungsten carbide reference sphere as prescribed by Foote et al. (1987).

Echosounder data were analyzed using SonarData's Echoview software. First, using the split-beam capabilities of each echosounder, all echoes from solitary individual targets, i.e. targets at densities lower than 1 per sampling volume, were identified as individual fish or marine mammals and removed from the data (MacLennan \& Simmonds 1992). A target strength threshold of $-75 \mathrm{~dB}$ was used along with a 'pulse length determination level,' the value in $\mathrm{dB}$ below peak value considered when determining the pulse length, or envelope, of a single-target detection, of $12 \mathrm{~dB}$. 'Normalized pulse lengths,' the measured pulse length divided by transmitted pulse length, were required to be between 0.8 and 2.0. The 'maximum beam compensation' to correct for transducer directivity was set to $12 \mathrm{~dB}$. To confirm that all sources of scattering within the measured pulse length were from a single target, all samples within this pulse envelope were required to have a standard deviation in angular position of $<3^{\circ}$ in both the along and athwart ship directions of the beam. The remaining volume scattering data were thresholded at a value of $-80 \mathrm{~dB}$ and integrated in $100 \mathrm{~m}$ horizontal by $1 \mathrm{~m}$ vertical bins. Numerical density of micronektonic animals for each $100 \mathrm{~m}$ along a transect nearest to a profiling station was calculated from volume scattering using echo energy integration, a technique that divides the total backscattered energy by the average backscatter energy from an individual animal to estimate the number of animals per unit volume sampled (MacLennan \& Simmonds 1992). The animal size and identity obtained in each $1 \mathrm{~m}$ depth range in the video camera system on the high-resolution profiler (see below) on each transect were combined with the relationships established by Benoit-Bird \& Au (2001) to calculate individual target strengths ranging from -66.4 to $-54.7 \mathrm{~dB} / / 1 \mathrm{~m}$ for individual shrimp and from -52.7 to $-38.8 \mathrm{~dB} / / 1 \mathrm{~m}$ in myctophid fishes. Density estimates for animals in the layers obtained from each acoustic 
frequency and those obtained independently with the camera system were then compared.

High resolution profiler. Casts to within $3 \mathrm{~m}$ of the bottom or to $300 \mathrm{~m}$, whichever was shallower, were conducted using the high-resolution profiler with a descent rate of approximately $10 \mathrm{~cm} \mathrm{~s}^{-1}$. The profiler was equipped with a number of instruments including an SBE-25 CTD (conductivity, temperature, pressure), a Wet Labs Wetstar chlorophyll fluorometer, an optical plankton counter (OPC), a Tracor acoustic profiling system (TAPS) for assessing zooplankton, and a lowlight video camera system to identify micronekton and measure animal size and numerical density.

Micronekton camera system. To ground truth the acoustic estimates of micronekton density, a 2-camera low-light video system with infrared illumination was used to obtain information on taxonomic composition, numerical density, and size of micronekton. The system, described by Benoit-Bird \& Au (2006), has shown no significant avoidance reaction by the micronekton unlike previous attempts with capture-based methods and visible light photography (e.g. Benoit-Bird \& Au 2001, 2003). Data were analyzed similarly to BenoitBird \& Au (2006). Video data for identification of species was analyzed by extracting still views every $0.25 \mathrm{~m}$ from each of the 2 cameras, which together had a sampling volume of $575 \mathrm{l}$. Animals seen in still views from both cameras were identified to the lowest taxonomic level possible, providing taxonomically-specific density measures in the measured volume of the overlapping fields of view. The coordinates of the identified animal and its apparent length were used to estimate its size. Measurements of size take into account the apparent length of the animal in both cameras, allowing their actual length to be determined using trigonometric relationships, eliminating apparent foreshortening from 1 camera. Data were averaged in $1 \mathrm{~m}$ depth bins to provide adequate sample sizes given the small sampling volume.

OPC. An OPC (Focal Technologies model OPC-1T) on the profiler provided the vertical distribution of particle abundance in sizes ranging from 0.25 to $20 \mathrm{~mm}$ (Herman 1988, 1992). The equivalent spherical diameter (ESD) was calculated according to the methods of Herman (1992) with a $15 \%$ increase to compensate for underestimation of size due to the random orientation of particles as they cross the OPC light beam, as proposed by Beaulieu et al. (1999). A flowmeter attached to the profiler was used to estimate of the volume of water sampled by the OPC. Data were measured as particle counts, and biovolume was estimated per $\mathrm{m}^{2}$ and per $\mathrm{m}^{3}$ for each cast.

TAPS. TAPS uses acoustical scattering at 6 frequencies to quantitatively estimate zooplankton abundance in size classes (Holliday \& Pieper 1995). TAPS operates at $265,420,700,1100,1850$, and $3000 \mathrm{kHz}$ and was used to collect volume scattering strength profiles. These measurements were transformed to estimates of zooplankton biovolume bin ESD classes via a constrained, non-linear, least-squares algorithm (Holliday 1977, MacLennan \& Simmonds 1992, Holliday \& Pieper 1995, Medwin \& Clay 1997) that employed a simple spherical model. The choice of a spherical model was guided by the body forms observed in net tow results, which consisted primarily of copepods with few elongate scatterers. These estimates of biovolume were converted to estimates of density by dividing the biovolume at a given size by the volume of a spherical animal of that ESD. Large individual targets (e.g. micronekton) were rarely sampled due to the small sample volume of TAPS (about 3 l).

Net tows. Vertically integrated net tows were conducted using a $333 \mu \mathrm{m}$ mesh, $0.75 \mathrm{~m}$ diameter ring net. The net was lowered until the weight located $3 \mathrm{~m}$ from the cod end reached the bottom, or until the net reached $100 \mathrm{~m}$ as identified on the echosounders, and then pulled to the surface at approximately $30 \mathrm{~m} \mathrm{~min}^{-1}$. During 2005, the net was equipped with a calibrated, custom-built flowmeter, and in 2006, with a calibrated TSK flowmeter to allow calculation of the volume of water sampled. Comparison of flowmeter readings and echosounder readings of net depth showed nearly identical estimates of the distance the net was pulled. Immediately after each tow, samples were rinsed through a series of sieves: $4 \mathrm{~mm}, 2 \mathrm{~mm}, 500 \mu \mathrm{m}$, and $250 \mu \mathrm{m}$. Each size fraction was preserved in a $90 \mathrm{ml}$ jar with a final concentration of $4 \%$ buffered formalin in seawater. Within 1 wk of preservation, the wet weight of each size fraction was measured by washing the sample onto a $9 \mathrm{~cm}$ diameter, $40 \mu \mathrm{m}$ particle retention size Whatman filter paper. The preservative solution was allowed to drain until no standing solution was left, and then more fluid was removed by 3 min under vacuum pressure. This procedure was followed on five $90 \mathrm{ml}$ volumes of $4 \%$ buffered formalin in seawater that did not contain a sample to obtain the weight of the empty filter paper. Each filter was then weighed on an analytical balance, and the sample rinsed back into the sample jar with the preservative solution. The weights of the wet control filters were within $\pm 2 \%$. The mean weight of the control filters was subtracted from the sample weight to provide a wet weight estimate. Samples that weighed within $\pm 5 \%$ of the mean of the control filters were assigned a wet weight of $0 \mathrm{mg}$. For analysis, all weights were converted to $\mathrm{mg}$ $\mathrm{m}^{-3}$.

After returning to the lab, individual zooplankton in the samples were identified. Because of the high diversity and relatively low abundance of individuals, many samples were counted in their entirety. Subsampling 
was conducted on dense samples so that at least 30 individuals were counted in each major taxonomic division in which animals were abundant. The smallest subsample was an eighth of the entire sample. For copepods, identification was typically to family with the abundant family Calanidae identified to genus and all copepods sorted by juvenile or adult form. For euphausiids and shrimp, identification was to species, and for other, less common groups, the level of identification depended on diversity within a group and the condition of the individual. Plankton from net tows were sorted into 99 categories that were then grouped into 17 major classes. These classes, with the number of categories separately identified in parentheses where appropriate, were as follows: copepods (juveniles and adults separately of 21 calanoid families, 2 cyclopoid, 2 harpacticoid, and 4 poecilostomid families, and copepod nauplii), fish larvae and eggs (3 groups including larval myctophids), urochordates (4 groups), protists (4 groups), malacostracans (11 species), ostractods, chaetognaths, gelatinous zooplankton (7 groups), crab zoea, mollusks (5 groups), amphipods, euphausiids (2 species, juveniles, and eggs), annelids (2 groups), holothurian larvae (echinoderm), bryozoans, isopods, and colonies of Trichodesmium thiebautii (a phytoplankton species). Based upon flowmeter readings and percentage of sample counted, these counts were then converted to numerical densities (ind. $\mathrm{m}^{-3}$ ).

Zooplankton data integration. Data from each TAPS and OPC cast were vertically integrated to a maximum depth of $100 \mathrm{~m}$ to allow comparison to the total zooplankton biomass measured in the net casts. Density of zooplankton in addition to total abundance likely plays an important role in successful micronekton foraging. The densities of zooplankton within depth intervals were calculated for the TAPS and OPC data. These results were compared to depth-specific densities of micronekton obtained from the echosounders and verified with the camera system. Total abundance and numerical density of micronekton and zooplankton were assessed as a function of distance from the shoreline and time using a multivariate analysis of variance (MANOVA). A simple MANOVA was chosen rather than a repeated measures ANOVA because it was highly unlikely that samples taken at a given location were dependent on samples taken previously at that same location for the following reasons: (1) sampling was never repeated at 1 site on the same day; (2) a reset in the distribution of micronekton and apparently zooplankton occurs daily; (3) previous work has shown that micronekton do not cue to the substrate (BenoitBird et al. 2001); and (4) the water is constantly moving, making results from an individual site different from one sample to the next. Zooplankton species distributions obtained from the net tows were also compared as a function of distance from the shoreline and time using single factor ANOVA. Levene's test of equality of error variances was conducted for each comparison, and an analysis of the residual values for each model was conducted to determine if they behaved randomly, ensuring that the data fulfill the assumptions of the ANOVA.

\section{RESULTS}

\section{February 2005}

\section{Zooplankton composition}

Zooplankton biomass from net tows was dominated by organisms between 2 and $4 \mathrm{~mm}$ in sieve size. Numerically, animals in this size range made up more than half of all samples.

Plankton from net tows were sorted into 99 categories that were then grouped into 17 major classes. Classes with mean densities greater than 1 ind. $\mathrm{m}^{-3}$ are listed in descending order by mean density: copepods (juveniles and adults separately of 21 calanoid families, 2 cyclopoid, 2 harpacticoid, and 4 poecilostomid families, and copepod nauplii), fish larvae and eggs, urochordates, protists, malacostracans, ostracods, chaetognaths, gelatinous zooplankton, crab zoea, mollusks, and amphipods. The total mean density of zooplankton over all net tows was 107.1 ind. $\mathrm{m}^{-3}$. Net samples were dominated by juvenile and adult copepods at densities averaging 69.7 ind. $\mathrm{m}^{-3}$, about $65 \%$ of all individuals. Of all copepods, approximately $40 \%$ were copepodite stages, and $60 \%$ were adults. Calanoid copepods made up about $75 \%$ of the copepods at an average density of 54.3 ind. $\mathrm{m}^{-3}$. Approximately $20 \%$ of the calanoids were Clausocalanus spp., which accounted for nearly $15 \%$ of all zooplankton by number. Other animals that had mean densities $>5$ ind. $\mathrm{m}^{-3}$ were Undinula, Euchaetidae, Pleuromamma, Acartia, and Lucicutiidae (all calanoid copepod genera or families), Oncaea (a poecilostomid copepod genus), Oithona (a cyclopoid copepod genus), transparent fish eggs, ostracods, a stomatopod species of shrimp, and spumellarian radiolarians.

Space-time distribution patterns

Micronketon distribution patterns are shown in Fig. 2. These patterns were consistent with those observed previously off the leeward coast of Oahu, Hawaii. Density estimates did not vary significantly between frequencies (ANOVA df $=3,216$, $p>0.05$ ). 


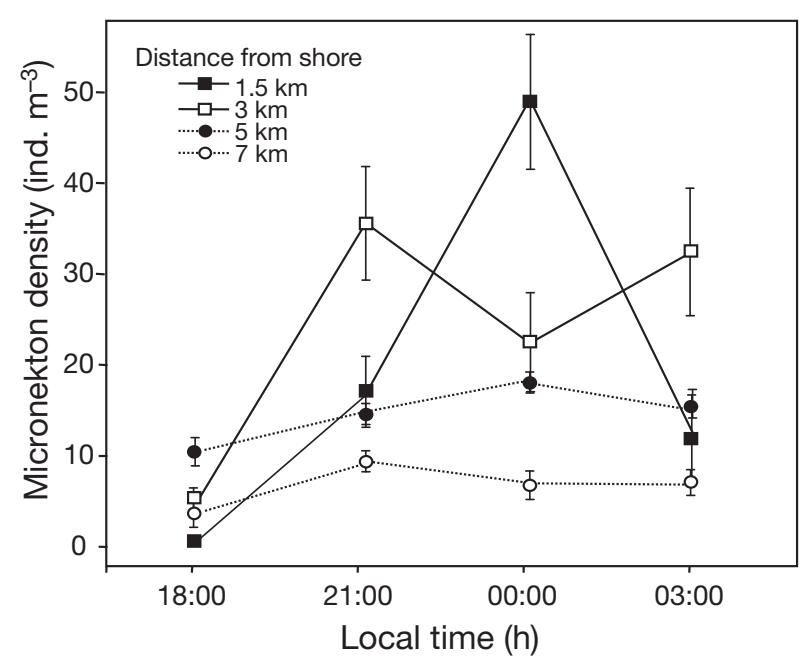

Fig. 2. Micronekton density within the scattering layer measured acoustically as a function of time and distance from the shoreline. February 2005 data from both sites are pooled, because although there were differences in the overall mean between sites, the time-distance from shore patterns were the same, thus increasing the $95 \%$ confidence intervals about each mean, which are indicated by error bars

For simplicity, only estimates calculated using the $70 \mathrm{kHz}$ echosounder, the same frequency used to sample the full range of the scattering layer throughout its migration by Benoit-Bird \& Au (2006), were used for further analysis. Density estimates made through echo energy integration at $70 \mathrm{kHz}$ were not significantly different from those made using the camera system (paired $t$-test, $\mathrm{p}>0.05,1-\beta=0.81$ ). In all estimates, more than $80 \%$ of the micronektonic animals identified with the camera system were myctophid fish. The majority of the remainder were midwater shrimp at least $3 \mathrm{~cm}$ in length. A MANOVA was conducted on various measures of micronekton abundance and density as a function of site, distance from shore, and time. The results are shown in Table 1.

A variety of density, biomass, biovolume, and abundance measurements of zooplankton were made using 3 different approaches: acoustic, optical counter, and net. The results of a MANOVA for the effects of site, time of night, and distance from shore on each measure of zooplankton are shown in Table 1. The results show strong similarities in pattern between measures and sampling systems. This can be seen by comparing Fig. 3, data from net samples, to Fig. 4, data from TAPS. These patterns in zooplankton are also quite similar to the time-space patterns observed in micronekton (Fig. 2). A similar analysis was carried out for raw fluorescence measured with the fluorometer on the vertical profiler. Results are also shown in Table 1.

A significant effect of site was observed for all micronekton abundance and density measures and

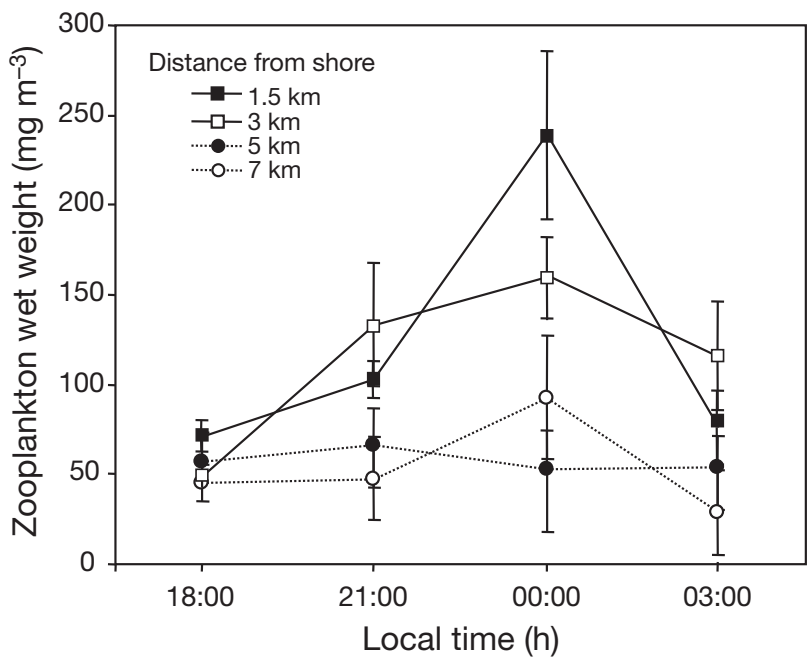

Fig. 3. Average wet weight of zooplankton captured in vertically integrated net tows for the entire water column to within $3 \mathrm{~m}$ of the bottom or $100 \mathrm{~m}$. February 2005 data from both sites are pooled because, although there were differences in the overall mean between sites, the time-distance from shore patterns were the same, thus increasing the $95 \%$ confidence intervals about each mean, which are indicated by error bars

nearly all measures of zooplankton (Table 1). There was no observed site effect on fluorescence. Post hoc tests revealed that the northern site consistently had a higher abundance and density of micronekton and zooplankton than the southern site. However, there

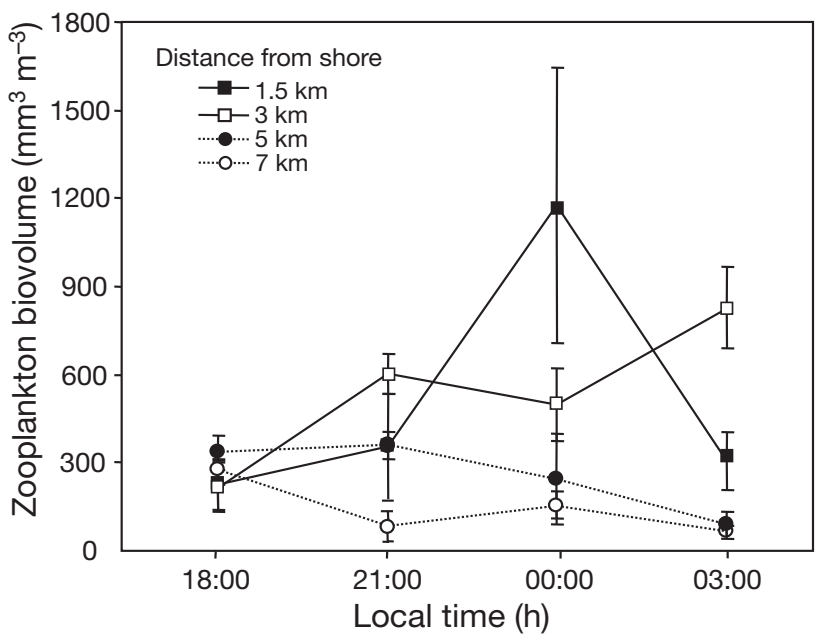

Fig. 4. Average biovolume of zooplankton for the entire water column to within $3 \mathrm{~m}$ of the bottom or $100 \mathrm{~m}$. Backscattering data from a Tracor acoustic profiling system (TAPS), a 6 frequency acoustic sensor attached to a vertical profiler, were transformed to estimates of zooplankton biovolume via a nonlinear least squares algorithm constrained by the types of zooplankton observed and their sizes. February 2005 data from both sites are pooled because, although there were differences in the overall mean between sites, the time-distance from shore patterns were the same, thus increasing the $95 \%$ confidence intervals about eachmean, which are indicated by error bars 
Table 1. February 2005 results of a MANOVA to observe the effects of site, distance from shore, and time of night on micronekton, zooplankton measured with several techniques, and chlorophyll fluorescence. $Z$ : individual zooplankters. p-values are indicated for significant results, ns: no significant effect $(p>0.05)$ of that factor on the variable

\begin{tabular}{|c|c|c|c|c|c|c|}
\hline & $\begin{array}{c}\text { Site } \\
(\mathrm{df}=1)\end{array}$ & $\begin{array}{c}\text { Distance from } \\
\text { shore } \\
(\mathrm{df}=3)\end{array}$ & $\begin{array}{c}\text { Time } \\
(\mathrm{df}=3)\end{array}$ & $\begin{array}{c}\text { Site } \times \\
\text { Distance } \\
(\mathrm{df}=9)\end{array}$ & $\begin{array}{c}\text { Site } \times \\
\text { Time } \\
(\mathrm{df}=3)\end{array}$ & $\begin{array}{c}\text { Distance } \times \\
\text { Time } \\
(\mathrm{df}=9)\end{array}$ \\
\hline \multicolumn{7}{|c|}{ Micronekton acoustics (error $\mathrm{df}=\mathbf{2 1 6}$ ) } \\
\hline Mean density (ind. $\mathrm{m}^{-3}$ ) & $<0.005$ & $<0.001$ & $<0.001$ & ns & ns & $<0.001$ \\
\hline Max density (ind. $\mathrm{m}^{-3}$ ) & $<0.005$ & $<0.001$ & $<0.001$ & ns & ns & $<0.001$ \\
\hline Abundance (ind. $\mathrm{m}^{-3}$ ) & $<0.001$ & $<0.001$ & $<0.001$ & ns & ns & $<0.001$ \\
\hline \multicolumn{7}{|c|}{ Zooplankton net tows $($ error $\mathrm{df}=334)$} \\
\hline \multicolumn{7}{|l|}{ Biomass (mg m³ ${ }^{-3}$} \\
\hline $500 \mu \mathrm{m}>Z>333 \mu \mathrm{m}$ & $<0.005$ & ns & ns & ns & ns & $<0.05$ \\
\hline $2 \mathrm{~mm}>Z>500 \mu \mathrm{m}$ & $<0.001$ & $<0.001$ & $<0.001$ & ns & ns & $<0.01$ \\
\hline $4 \mathrm{~mm}>Z>2 \mathrm{~mm}$ & ns & $<0.001$ & $<0.001$ & ns & ns & $<0.05$ \\
\hline$Z>4 \mathrm{~mm}$ & $<0.005$ & ns & ns & ns & ns & ns \\
\hline All sizes & ns & $<0.001$ & $<0.001$ & ns & ns & $<0.05$ \\
\hline \multicolumn{7}{|l|}{ Total biomass $\left(\mathrm{mg} \mathrm{m}^{-2}\right.$ ) } \\
\hline $500 \mu \mathrm{m}>Z>333 \mu \mathrm{m}$ & $<0.005$ & ns & ns & ns & ns & $<0.05$ \\
\hline $2 \mathrm{~mm}>Z>500 \mu \mathrm{m}$ & $<0.001$ & $<0.001$ & $<0.001$ & ns & ns & $<0.001$ \\
\hline $4 \mathrm{~mm}>Z>2 \mathrm{~mm}$ & ns & $<0.005$ & $<0.001$ & ns & ns & $<0.05$ \\
\hline$Z>4 \mathrm{~mm}$ & $<0.001$ & ns & ns & ns & ns & ns \\
\hline All sizes & ns & $<0.01$ & $<0.005$ & ns & ns & $<0.05$ \\
\hline \multicolumn{7}{|l|}{ Density (ind. $\mathrm{m}^{-3}$ ) } \\
\hline $500 \mu \mathrm{m}>Z>333 \mu \mathrm{m}$ & $<0.01$ & ns & ns & ns & ns & $<0.01$ \\
\hline $2 \mathrm{~mm}>Z>500 \mu \mathrm{m}$ & $\mathrm{ns}$ & $<0.001$ & $<0.05$ & ns & ns & $<0.005$ \\
\hline $4 \mathrm{~mm}>Z>2 \mathrm{~mm}$ & $<0.05$ & ns & ns & ns & ns & $<0.001$ \\
\hline$Z>4 \mathrm{~mm}$ & $<0.005$ & ns & ns & ns & ns & $<0.01$ \\
\hline All sizes & $<0.01$ & $<0.05$ & $<0.005$ & ns & ns & $<0.005$ \\
\hline \multicolumn{7}{|l|}{ Abundance (ind. $\mathrm{m}^{-2}$ ) } \\
\hline $500 \mu \mathrm{m}>Z>333 \mu \mathrm{m}$ & $<0.01$ & ns & ns & ns & ns & $<0.05$ \\
\hline $2 \mathrm{~mm}>Z>500 \mu \mathrm{m}$ & $<0.05$ & $<0.001$ & $<0.01$ & ns & ns & $<0.05$ \\
\hline $4 \mathrm{~mm}>Z>2 \mathrm{~mm}$ & $<0.01$ & ns & ns & ns & ns & $<0.001$ \\
\hline$Z>4 \mathrm{~mm}$ & $<0.005$ & ns & ns & ns & ns & $<0.01$ \\
\hline All sizes & $<0.005$ & $<0.05$ & $<0.05$ & ns & ns & $<0.05$ \\
\hline \multicolumn{7}{|c|}{ Zooplankton TAPS $($ error $\mathrm{df}=\mathbf{2 1 6}$ ) } \\
\hline Biovolume $\left(\mathrm{mm}^{3} \mathrm{~m}^{-3}\right)$ & $<0.01$ & $<0.01$ & $<0.05$ & ns & ns & $<0.001$ \\
\hline Max biovolume $\left(\mathrm{mm}^{3} \mathrm{~m}^{-3}\right)$ & $<0.01$ & $<0.005$ & $<0.001$ & ns & ns & $<0.001$ \\
\hline Total biovolume $\left(\mathrm{mm}^{3} \mathrm{~m}^{-2}\right)$ & $<0.01$ & $<0.001$ & $<0.01$ & ns & ns & $<0.001$ \\
\hline \multicolumn{7}{|c|}{ Zooplankton OPC $($ error $\mathrm{df}=216)$} \\
\hline Biovolume $\left(\mathrm{mm}^{3} \mathrm{~m}^{-3}\right)$ & $<0.01$ & $<0.01$ & $<0.01$ & ns & ns & $<0.001$ \\
\hline Max biovolume $\left(\mathrm{mm}^{3} \mathrm{~m}^{-3}\right)$ & $<0.01$ & $<0.005$ & $<0.001$ & ns & ns & $<0.001$ \\
\hline Total biovolume $\left(\mathrm{mm}^{3} \mathrm{~m}^{-2}\right)$ & $<0.005$ & $<0.01$ & $<0.01$ & ns & ns & $<0.001$ \\
\hline Mean density (counts $\mathrm{m}^{-3}$ ) & $<0.01$ & $<0.001$ & $<0.01$ & ns & ns & $<0.01$ \\
\hline Max density (counts $\mathrm{m}^{-3}$ ) & $<0.01$ & $<0.001$ & $<0.005$ & ns & ns & $<0.01$ \\
\hline Abundance (counts $\mathrm{m}^{-2}$ ) & $<0.01$ & $<0.001$ & $<0.01$ & ns & ns & $<0.01$ \\
\hline \multicolumn{7}{|c|}{ Chlorophyll fluorescence $($ error $\mathrm{df}=216$ ) } \\
\hline Mean chl $\left(\mathrm{mg} \mathrm{m}^{-3}\right)$ & ns & ns & ns & ns & ns & ns \\
\hline $\operatorname{Max} \mathrm{chl}\left(\mathrm{mg} \mathrm{m}^{-3}\right)$ & ns & ns & ns & ns & ns & ns \\
\hline Total chl $\left(\mathrm{mg} \mathrm{m}^{-2}\right)$ & ns & $<0.01$ & $<0.01$ & ns & ns & ns \\
\hline
\end{tabular}

were no significant interaction terms involving site, suggesting that the across slope space-time patterns are similar between sites.

Micronekton measures and many zooplankton measures showed significant time-of-day and distancefrom-shore effects. A significant interaction effect of time-of-day and distance-from shore was observed for all micronekton and nearly all zooplankton measures (Figs. 2 to 4 ).
Nearshore-offshore gradients

The strong interactions observed between time and distance from shore on measures of zooplankton abundance necessitate a simplification in the analyses to test the hypothesis that zooplankton abundance is higher in surface waters nearshore than offshore. Micronekton are primarily found in nearshore waters near the middle of the night (Fig. 2). A 
MANOVA was conducted to test the effects of distance from shore on the density of zooplankton in each of the 17 major taxonomic classes and 1 subclass, calanoid copepods, as well as total zooplankton density from all net tows in the hour after midnight when the greatest number of micronekton were found at the stations closest to shore (Table 2). For groups that were significantly affected by distance from shore, a series of post hoc tests was used to determine whether densities in each group were higher nearshore than at the next distance farther offshore. A Bonferroni correction was used to compensate for multiple comparisons. Because the hypothesis was that nearshore transects would have higher densities than offshore transects, all tests were 1-tailed. The mean densities for each zooplankton group in each distance class are shown in Table 2 , as are the results of the post hoc analyses. A similar analysis of distance effect on the density of the 99 groups originally identified from the net tows was carried out. The taxonomic groups that were significantly affected by distance from the shoreline in midnight samples are shown in Table 3. Post hoc analyses were corrected using the Bonferroni method. Finally, an ANOVA on the biomass density $\left(\mathrm{mg} \mathrm{m} \mathrm{m}^{-3}\right)$ from net tows showed a similar pattern with a significant effect of distance $(\mathrm{p}<0.01)$ and significant 1-tailed differences between each adja- cent distance $(1.5-3.0 \mathrm{~km}: \mathrm{p}<0.005 ; 3.0-5.0 \mathrm{~km}: \mathrm{p}<$ $0.01 ; 5.0-7.0 \mathrm{~km}: \mathrm{p}<0.05)$.

\section{Comparison of zooplankton techniques}

A variety of techniques was used to quantify zooplankton abundance and density. All 3 methods showed similar results with respect to the nearshoreoffshore hypothesis, as indicated by the statistical results shown in Table 1. To quantify the ability of each method to measure the abundance of zooplankton, the estimates of density of zooplankton $>0.5 \mathrm{~mm}$ in size, the minimum size for the OPC and a sieve mesh size, was compared for net tows, TAPS, and the OPC for the February 2005 data. Fig. 5 shows a series of pairwise linear regressions comparing each method. None of the slopes is significantly different from $1(p>0.05)$ for all comparisons, the $y$-intercepts are very close to 0 , and for all regressions the variation in zooplankton density measured with 1 technique that could be explained by the variation in zooplankton density measured with a different technique was greater than $90 \%$.

The mean density of zooplankton by the sieve size classes used for net sampling during February 2005 is shown for all 3 methods in Fig. 6. Fig. 7 shows the density of zooplankton by size for TAPS and OPC data in $0.2 \mathrm{~mm}$ increments. In these data sets, very few zoo-

Table 2. Results of a MANOVA of the effect of distance from shore on the density of plankton in 17 large taxonomic groups identified from February 2005 net tows in the hour following midnight are shown in the second column. p-values are indicated for significant results; ns: no significant effect of that factor on the variable $(\mathrm{p}>0.05)$. The next 4 columns show the mean density of individuals in each group for all midnight net tow samples at each distance from shore. The results of 1-tailed post hoc comparisons for those groups that showed a significant distance effect on numerical density of plankton are shown in the last 3 columns

\begin{tabular}{|c|c|c|c|c|c|c|c|c|}
\hline \multirow[t]{2}{*}{ Plankton group } & \multirow{2}{*}{$\begin{array}{l}\text { Distance effect }(p) \\
\quad(\mathrm{df}=3,334)\end{array}$} & \multicolumn{4}{|c|}{ Midnight mean density (ind. $\mathrm{m}^{-3}$ ) } & \multicolumn{3}{|c|}{ Post hoc comparisons (p) } \\
\hline & & $1.5 \mathrm{~km}$ & $3.0 \mathrm{~km}$ & $5.0 \mathrm{~km}$ & $7.0 \mathrm{~km}$ & $1.5-3 \mathrm{~km}$ & $3-5 \mathrm{~km}$ & $5-7 \mathrm{~km}$ \\
\hline All Copepoda & $<0.05$ & 227.2 & 167.2 & 98.1 & 50.4 & $<0.05$ & $<0.05$ & $<0.05$ \\
\hline All calanoid copepods & $<0.05$ & 182.8 & 94.3 & 78.5 & 37.0 & $<0.05$ & $<0.05$ & $<0.05$ \\
\hline Amphipoda & ns & 3.7 & 1.8 & 1.7 & 1.9 & - & - & - \\
\hline Isopoda & ns & 0.1 & 0.0 & 0.0 & 0.0 & - & - & - \\
\hline Ostracods & ns & 13.7 & 4.1 & 4.5 & 4.9 & - & - & - \\
\hline Euphausiia & $<0.05$ & 1.1 & 0.6 & 0.4 & 0.3 & $<0.05$ & ns & ns \\
\hline Crab zoea & $<0.05$ & 17.2 & 1.3 & 0.9 & 0.8 & $<0.05$ & $\mathrm{~ns}$ & $\mathrm{~ns}$ \\
\hline Shrimp (decapoda) & $<0.05$ & 18.7 & 6.2 & 3.5 & 1.8 & $<0.05$ & ns & ns \\
\hline Chaetognatha & $\mathrm{ns}$ & 4.8 & 1.7 & 1.5 & 1.4 & - & - & \\
\hline Urochordata & $<0.05$ & 10.4 & 3.2 & 4.1 & 4.8 & $<0.05$ & ns & ns \\
\hline Fish & $<0.05$ & 20.4 & 4.2 & 4.4 & 4.1 & $<0.05$ & ns & ns \\
\hline Gelatinous & ns & 5.6 & 1.0 & 1.4 & 2.0 & - & - & - \\
\hline Protista & ns & 9.2 & 4.6 & 7.8 & 6.1 & - & - & - \\
\hline Annelida & ns & 0.3 & 0.3 & 0.3 & 0.4 & - & - & - \\
\hline Molluska & ns & 6.3 & 2.1 & 2.3 & 2.1 & - & - & - \\
\hline Bryozoa & ns & 0.0 & 0.0 & 0.1 & 0.1 & - & - & - \\
\hline Holothuroidia larva & ns & 0.9 & 0.3 & 0.4 & 0.2 & - & - & - \\
\hline Trichodesmium colony & ns & 0.0 & 0.0 & 0.0 & 0.0 & - & - & - \\
\hline Total density & $<0.05$ & 339.4 & 198.5 & 131.4 & 81.3 & $<0.05$ & $<0.05$ & $<0.05$ \\
\hline
\end{tabular}


Table 3. Results of a MANOVA of the effect of distance from shore on the numerical density of plankton in the original 99 groups identified from February 2005 net tows in the hour following midnight are shown in the second column. p-values are indicated for significant results while groups that showed no significant effect are not shown. The next 4 columns show the mean density of zooplankton in each category for all midnight net tow samples at each distance from shore. The results of 1-tailed post hoc comparisons for those groups that showed a significant distance effect on zooplankton density are shown in the last 3 columns. ns: $p>0.05$

\begin{tabular}{|c|c|c|c|c|c|c|c|c|}
\hline \multirow[t]{2}{*}{ Plankton group } & \multirow{2}{*}{$\begin{array}{l}\text { Distance effect }(p) \\
\qquad d f=3,334\end{array}$} & \multicolumn{4}{|c|}{ Midnight mean density (ind. $\mathrm{m}^{-3}$ ) } & \multicolumn{3}{|c|}{ Post hoc comparisons (p) } \\
\hline & & $1.5 \mathrm{~km}$ & $3.0 \mathrm{~km}$ & $5.0 \mathrm{~km}$ & $7.0 \mathrm{~km}$ & $1.5-3 \mathrm{~km}$ & $3-5 \mathrm{~km}$ & $5-7 \mathrm{~km}$ \\
\hline Adult Acartia (calanoid) & $<0.05$ & 14.8 & 8.9 & 5.8 & 2.4 & $<0.05$ & $<0.05$ & $<0.05$ \\
\hline Adult Clausocalanus (calanoid) & $<0.05$ & 36.7 & 20.8 & 16.4 & 12.9 & $<0.05$ & $<0.05$ & $<0.05$ \\
\hline Adult Eucalanoidae (calanoid) & $<0.05$ & 1.4 & 1.1 & 0.8 & 0.1 & $<0.05$ & $<0.05$ & $<0.05$ \\
\hline Juvenile Euchaetidae (calanoid) & d) $<0.05$ & 21.4 & 6.7 & 5.9 & 5.5 & $<0.05$ & ns & ns \\
\hline Juvenile Lucicutiidae (calanoid) & d) $<0.05$ & 6.1 & 3.7 & 1.2 & 0.6 & $<0.05$ & $<0.05$ & $<0.05$ \\
\hline Adult Scolecithrix (calanoid) & $<0.05$ & 4.6 & 2.4 & 1.5 & 0.3 & $<0.05$ & $<0.05$ & $<0.05$ \\
\hline Juvenile Scolecithrix (calanoid) & $<0.05$ & 9.5 & 6.2 & 3.3 & 0.6 & $<0.05$ & $<0.05$ & $<0.05$ \\
\hline Oithonidae (cyclopoid) & $<0.05$ & 18.7 & 2.8 & 3.6 & 4.9 & $<0.05$ & ns & ns \\
\hline Copilia (poecilostomid) & $<0.05$ & 2.2 & 1.2 & 0.1 & 0.1 & $<0.05$ & $<0.05$ & ns \\
\hline Euphausiid calyptopis stage & $<0.05$ & 0.7 & 0.1 & 0.1 & 0.1 & $<0.05$ & ns & ns \\
\hline Crab zoea & $<0.05$ & 17.2 & 6.1 & 0.9 & 0.8 & $<0.05$ & $<0.05$ & ns \\
\hline Stomatopod shrimp sp. & $<0.05$ & 16.8 & 3.5 & 1.5 & 1.2 & $<0.05$ & $<0.05$ & ns \\
\hline Chaetognatha & $<0.05$ & 4.8 & 2.6 & 1.2 & 1.4 & $<0.05$ & $<0.05$ & ns \\
\hline Apendicularia & $<0.05$ & 9.9 & 0.7 & 1.4 & 1.8 & $<0.05$ & ns & ns \\
\hline Transparent fish egg & $<0.05$ & 18.6 & 3.9 & 3.5 & 3.7 & $<0.05$ & ns & ns \\
\hline Opaque fish egg & $<0.05$ & 1.1 & 0.2 & 0.2 & 0.2 & $<0.05$ & ns & ns \\
\hline Larval Myctophidae (fish) & $<0.05$ & 0.7 & 0.0 & 0.1 & 0.2 & $<0.05$ & ns & ns \\
\hline Siphonophora & $<0.05$ & 1.8 & 0.3 & 0.3 & 0.5 & $<0.05$ & ns & ns \\
\hline Pelagic Gastropoda & $<0.05$ & 5.1 & 3.3 & 1.5 & 1.4 & $<0.05$ & $<0.05$ & ns \\
\hline
\end{tabular}

plankton were observed with an equivalent spherical diameter $>3.5 \mathrm{~mm}$ and so are not shown.

\section{Vertical distribution}

The vertical distribution of zooplankton was measured with TAPS and the OPC. The zooplankton vertical distribution was highly variable with sharp discontinuities in zooplankton that represent order of magnitude changes in biovolume or density in $<1 \mathrm{~m}$ change in depth. An example cast is shown in Fig. 8. Despite this intense vertical variation, the results from the TAPS and OPC on the same cast were very similar, and replicate profiles showed repeatable patterns. The example cast shown in Fig. 8 shows distinct size classes present in each peak of zooplankton biovolume. Distinct peaks in the zooplankton vertical structure were associated with differences in the size of the particles in many of the casts.

In both the TAPS and OPC data, the center of the zooplankton distribution, i.e. the depth at which half of the biovolume for the TAPS or density for the OPC was above that point and half below it, was not significantly affected by time ( $p>0.05$ for both methods) but did show a significant effect in response to distance from shore (TAPS data: $\mathrm{p}<0.01$; OPC data: $\mathrm{p}<0.005$ ) with a shallowing of the center of the zooplankton distribution inshore, in shallow water. Neither measure showed a significant interaction effect between time and distance from the shoreline. The center depth of zooplankton was always less than the midpoint of the profile at the location of the cast. The difference between the center depth and midpoint depth was not significantly affected by time ( $p>0.05$ for both comparisons) but was affected by distance from the shoreline (TAPS data: $\mathrm{p}<0.05$; OPC data: $\mathrm{p}<0.01$ ) with sites closer to shore and thus in shallower water showing less of a difference between the center and midpoint depths than those farther from shore. Neither showed a significant interaction term. These results do not show a clear vertical shift in the distribution of overall zooplankton biomass as a function of time as would be expected during diel migration synchronized among various zooplankton taxa. Rather, overall zooplankton depth appears tied to seafloor depth as it shallows closer to the shoreline, regardless of time of night.

\section{April/May 2005 and 2006}

Micronekton distribution patterns in April/May samples of both years were nearly identical to those observed in February 2005. ANOVAs for the April/ May 2005 and 2006 data both showed significant effects $(p<0.01)$ of time, distance from shore, and the interaction of these 2 variables for all measures of micronekton shown in Table 1, supporting the obser- 
vation that the distribution patterns of micronekton are similar in all study periods.

A MANOVA for all micronekton and zooplankton measures shown in Table 1 was conducted on the combined February 2005 and April/May 2005 and 2006
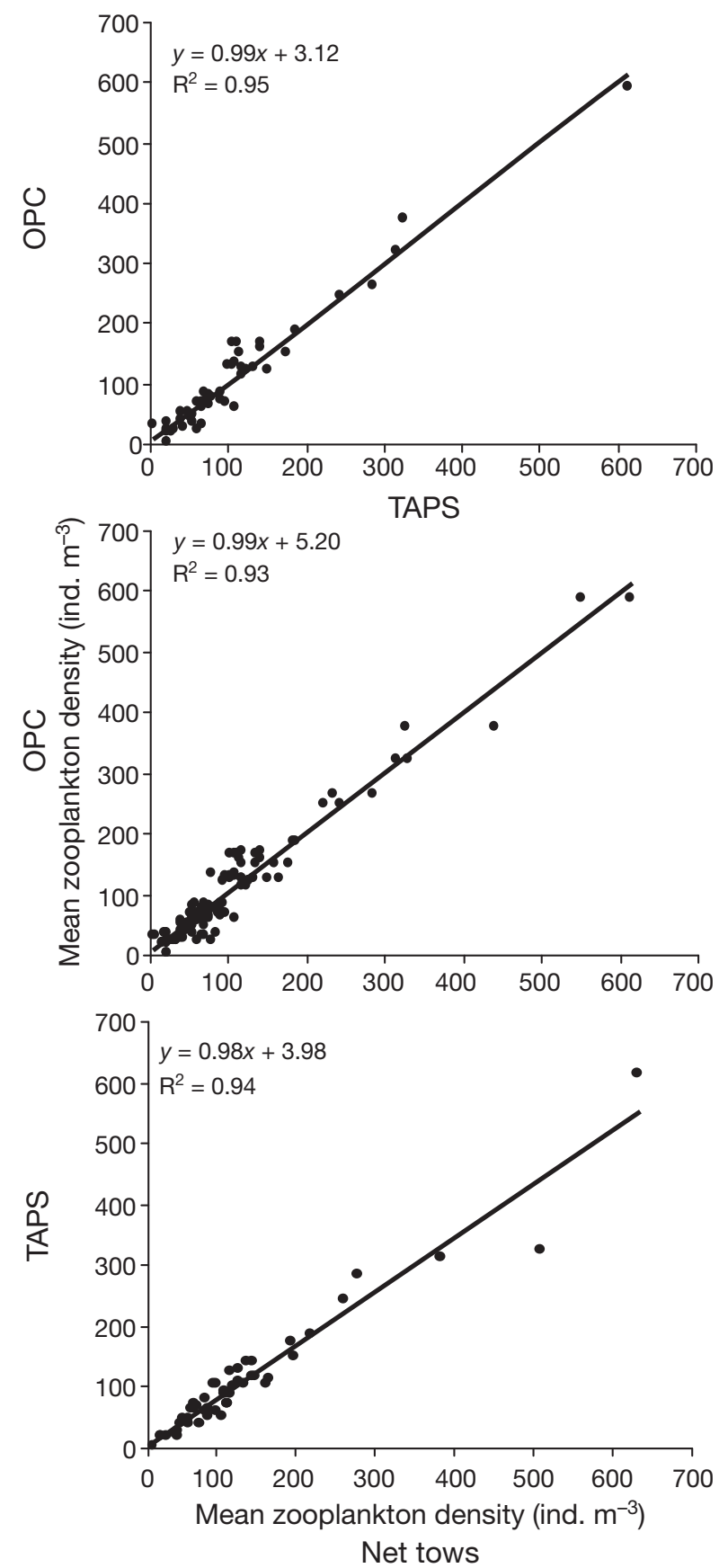

Fig. 5. Mean density of all zooplankton $>500 \mathrm{~mm}$ in size are compared between each of the 3 methods used during the February 2005 cruise. The equation of the best fit linear regression through each pair of data as well as the goodness of fit of the regression are shown for each comparison. OPC: optical plankton counter; TAPS: Tracor acoustic profiling system data to determine if these different sampling cruises showed different patterns. The effects of site ( $\mathrm{df}=$ $1,132)$, time $(\mathrm{df}=2,132)$, distance from shore $(\mathrm{df}=$ $1,132)$, and cruise ( $\mathrm{df}=1,132)$ were assessed. The result showed no significant effect of cruise on any of the measures and no significant interaction terms involving cruise.

Zooplankton identified from net tows were primarily the same taxonomic groups as those observed in Feb-
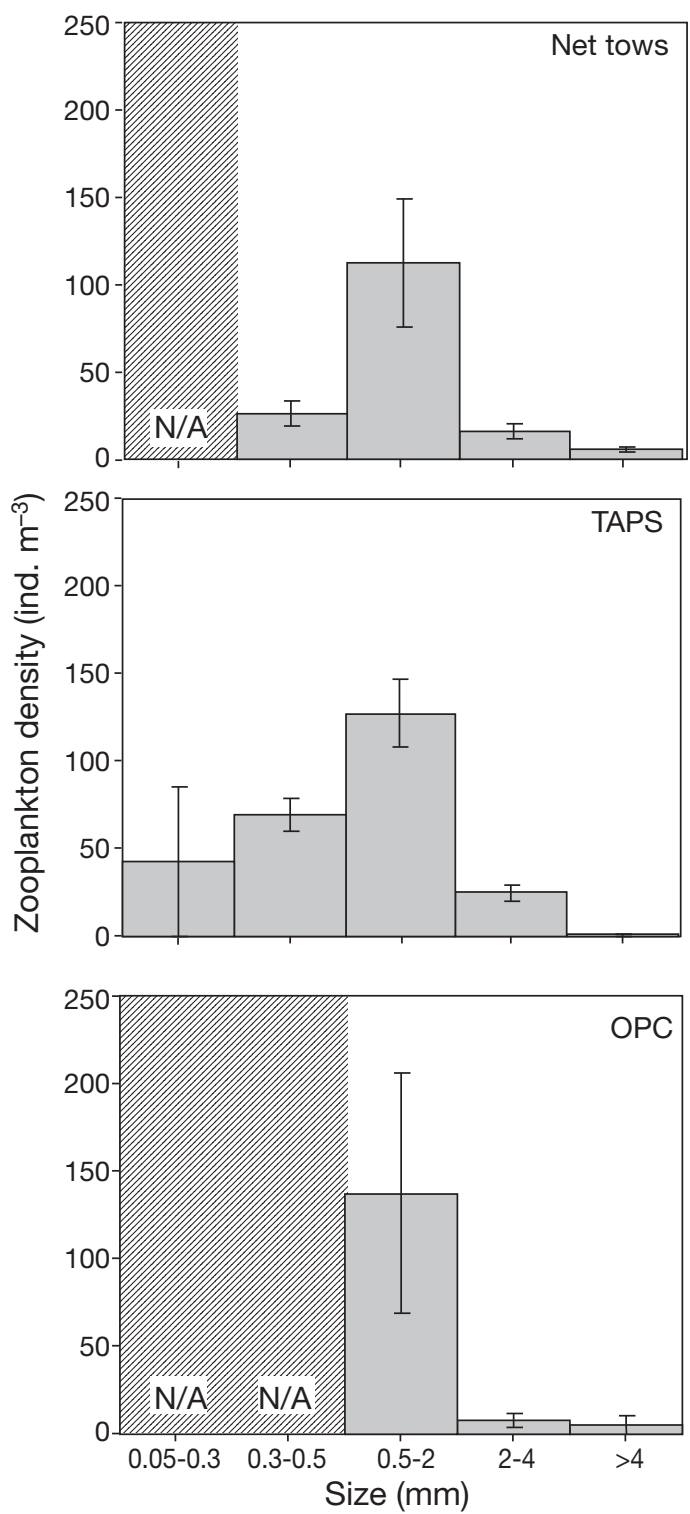

Fig. 6. Mean density of zooplankton as a function of size class for each of the 3 methods used during the February 2005 cruise. Size classes equate to the sieve sizes used to sort live zooplankton samples from net tows as well as 1 size class smaller than the net mesh. Hatched areas show size classes at which an individual method cannot be applied. Error bars indicate the $95 \%$ confidence intervals about the mean. OPC: optical plankton counter; TAPS: Tracor acoustic profiling system 


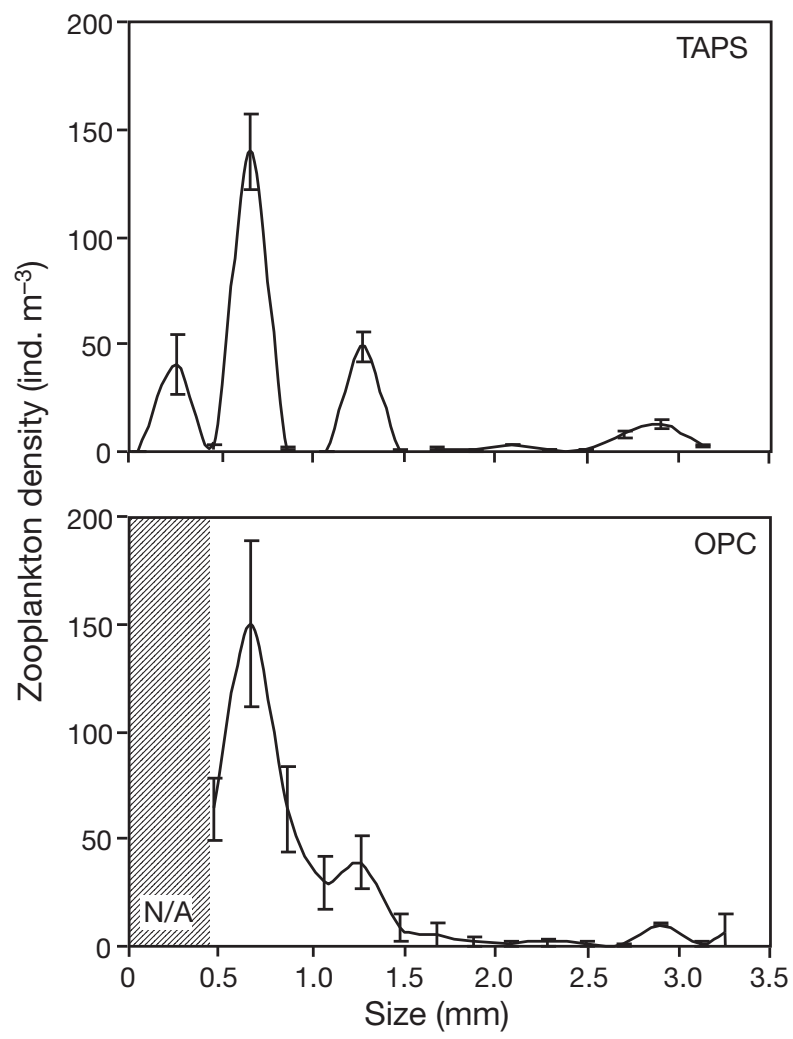

Fig. 7. Mean density of zooplankton integrated over the upper $100 \mathrm{~m}$ of the water column. Data were taken during the February 2005 cruise using Tracor acoustic profiling system (TAPS) and the optical plankton counter (OPC) and are shown as a function of the size classes used in the TAPS model. Very few individuals greater than $3.5 \mathrm{~mm}$ in size were observed and so are not shown. Hatched area highlights zooplankton sizes smaller than the OPC can detect. Both data are shown with the same size bins. Error bars indicate the 95\% confidence intervals about the mean. For the TAPS data, some error bars were too small to be represented

ruary 2005 and in nearly the same order of relative importance, with the exception of a significant number of mysids in April/May 2005 at the southern site that were not observed in the February samples that year. For both the April/May 2005 and 2006 data, the patterns of zooplankton distribution were very similar to the February 2005 samples with significant effects of time, distance from the shoreline, and a significant interaction between the two observed on most measures of zooplankton from all 3 techniques. Considering only the density data within $1 \mathrm{~h}$ following midnight, a significant effect of distance from the shoreline was identified in both data sets for total copepods, total calanoid copepods, euphausiids, crab zoea, shrimp, and fish. In April/May 2005, mollusks also showed this effect and in April/May 2006, urochordates (salps, doliolids, and appendicularians) showed an effect of distance from shore. These are primarily the same groups whose densities were significantly affected by distance from the shore at midnight in February 2005 (Table 2). Considering the individually identified groups, distance-from-shore results were quite similar to those from February 2005, with a few additional calanoid copepod groups showing a significant distance effect in April/May 2005 (juvenile Haloptilus, juvenile and adult Pontellidae), as well as one calanoid group that did not show a distance effect in April/May that did in February 2005 (Euchetiidae). Similarly, in April/May 2006, salps and Oncaea (poecilostomid copepod) showed a significant distance effect, while euphausiids at the calyptosis stage did not. One-tailed post hoc tests showed that in April/May 2005, the density of each group shown to have a significant distancefrom-shore effect was significantly higher at 1.0 than $1.5 \mathrm{~km}$ from the shoreline, and greater at 1.5 than 3.0 $\mathrm{km}$ from the shoreline. One-tailed post hoc tests were conducted on zooplankton density for each group that showed a significant distance-from-shore effect in April/May 2006. These analyses revealed that the density of each zooplankton group was greater at 1.0 than 1.5 , greater at 1.5 than 2.0 , and greater at 2.0 than $3.0 \mathrm{~km}$ from the shore.

\section{DISCUSSION}

Our goal was to determine whether food availability could provide an adaptive explanation for the nearshore migration of micronekton of the scattering layer around the Hawaiian Islands by simultaneously measuring the movements of the mesopelagic layer of micronekton and the density, abundance, and identity of potential zooplankton prey. We tested the prediction that zooplankton biomass or density would be higher nearshore than offshore during nighttime hours when migrating micronekton species are feeding (Clarke 1978). Our results show that while there was a significant nearshore-offshore effect on zooplankton in the upper $100 \mathrm{~m}$ for some measures, the biomass, density, and biovolume of nearly every size class of zooplankton from 3 different techniques was strongly affected by the interaction of distance from shore and time, meaning that the horizontal distribution pattern in the upper $100 \mathrm{~m}$ is changing over the course of a day. An increasingly strong nearshore to offshore gradient in zooplankton was observed between 18:00 h and midnight, with a decreasing difference between nearshore and offshore locations toward morning. This pattern of an increase in zooplankton density, total numbers, and biomass in the upper water column nearshore relative to offshore near the middle of the night was consistent between the 2 sampling sites studied and over 3 sampling periods covering winter and spring in 2 different 

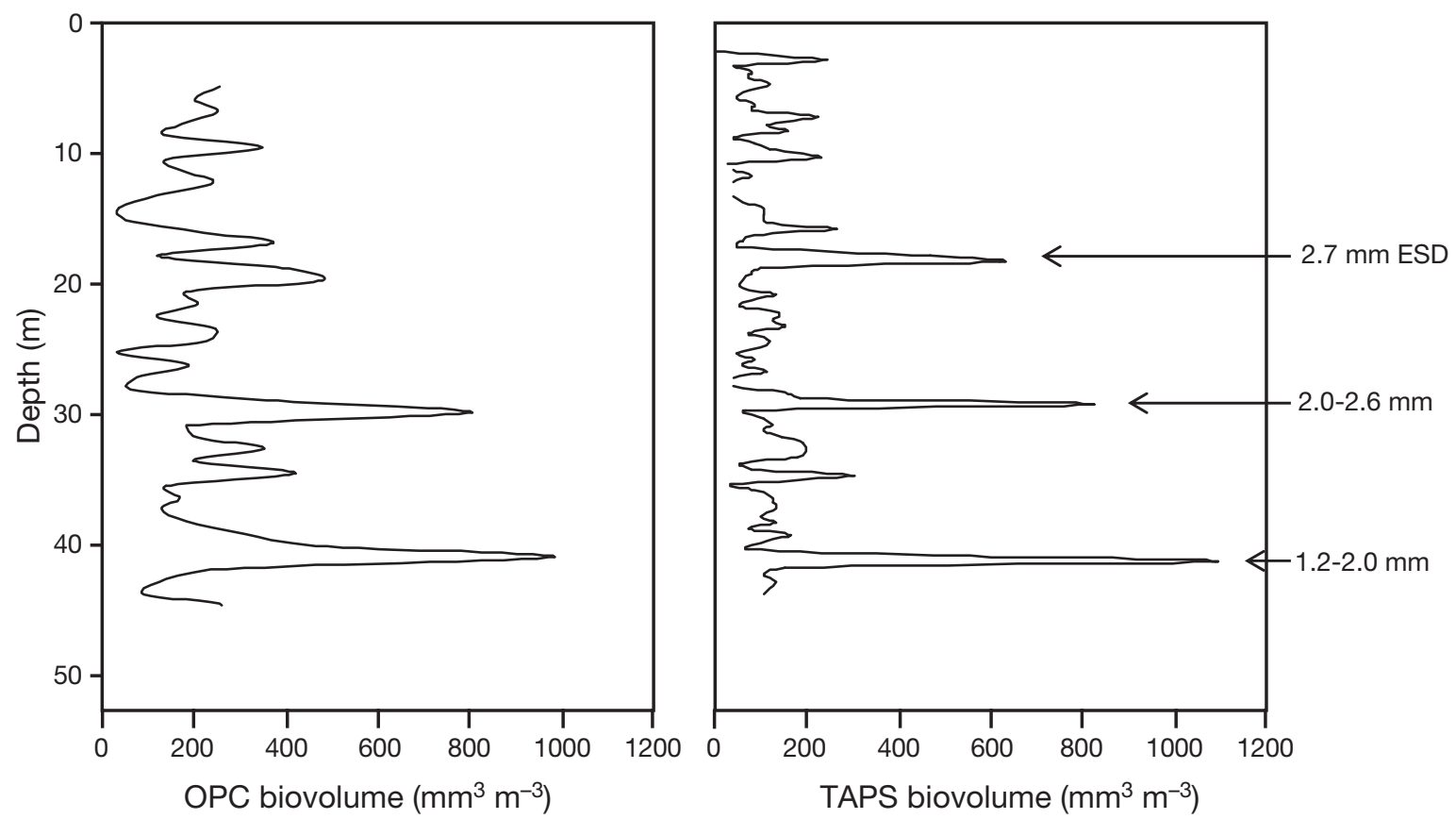

Fig. 8. Zooplankton biovolume measured by the optical plankton counter (OPC left) and Tracor acoustic profiling system (TAPS right), both in $0.5 \mathrm{~m}$ vertical bins, as a function of depth on 22 February 2005, 00:12 h local time $5 \mathrm{~km}$ from shore. This cast had a total biovolume that was approximately the same as the average for all casts. The vertical structure was similar between the OPC and TAPS measurements. In this example, 3 distinct peaks are observed in zooplankton biovolume. Each peak is dominated by different sized zooplankton. Equivalent spherical diameters (ESD) observed in each peak are shown

years. This suggests that this pattern is consistent along the leeward coast of Oahu over a significant portion of the year and from year to year and is likely to be an ecologically important pattern of resource distribution.

The observed zooplankton distribution should favor the nearshore-offshore migration of micronekton observed at the same time and examined in more detail in recent work (Benoit-Bird et al. 2001, Benoit-Bird \& $\mathrm{Au}$ 2006, McManus et al. 2008). The results of our study show that the density of micronekton is correlated with simultaneous measures of zooplankton abundance. Increases in micronekton occur at the same relative position and at nearly the same time as increases in zooplankton. No gut content information is available from the micronekton during their horizontal migration because of the difficulties of capturing these highly mobile animals in shallow water. We therefore cannot test when feeding occurs. However, the observed diel vertical and horizontal migration would allow micronekton access to 5-6 times greater biomass, density, and abundance of zooplankton than would diel vertical migration alone.

The observed pattern in zooplankton could result from either benthic emergence or vertical migration coupled with horizontal movement through either active swimming or passive advection. While not specifically tested in the study, the taxonomic composi- tion of net samples, specifically the taxa that showed nearshore-offshore patterns, reveals the potential importance of each proposed mechanism. Zooplankton were diverse, although both biomass and density were dominated by copepods, specifically calanoids. Of the 99 groups into which zooplankton from net tows were sorted, 24 showed a significant effect of distance from the shoreline in their densities at midnight during at least 1 cruise. All 24 groups showed a higher concentration of individuals nearshore compared to transects farther from shore, with the distance over which the change occurred varying between taxa. Taxa that showed nearshore-offshore patterns included a variety of forms. Fish eggs showed a higher concentration at $1.5 \mathrm{~km}$ from the shoreline than at any other site, which is likely due to the spawning behavior of adult fish that were not sampled. All other taxa showing nearshore to offshore gradients were mobile and belonged to groups known to be primarily or exclusively pelagic rather than benthic or epibenthic species. Some groups are coastal (the calalanoid copepods Acartia and Clausocalanus); some are primarily known from deep-water areas (calanoid copepods Eucalanoidae, Euchatidae, Lucicutiidae, and Scolecithrix, and cyclopoid copepods from the family Oithonidae). Many groups that show this nearshore-offshore gradient commonly migrate vertically (Calanoidae: Scolecithrix; Poecilostomidae: Copilia and Oncaea; calypto- 
sis stage euphausiids). Groups that did not show a nearshore-offshore gradient were from both pelagic taxa (Calanoidae: Calanidae, Candacia, Centropages, Eucalanus, Mecynocera, Pleuromamma spp.) and bottom-associated taxa (Calanoidae: Aetideus; Harpacticoida: Miraciidae). Several of these groups exhibit marked vertical migrations (Calanoidae: Calanidae, Pleuromamma sp.). The identification of significant nearshore-offshore gradients only in pelagic taxa does not support benthic emergence as a mechanism for the observed increase in zooplankton nearshore at midnight. Vertical migration combined with other behavioral and physical processes may indeed be important mechanisms by which zooplankton aggregate nearshore, e.g. through trapping of vertically migrating zooplankton over shallow shelves as has been observed in other steep slope habitats (Boehlert et al. 1992, Dower \& Brodeur 2004, Genin 2004). However, not all groups that vertically migrate show a nearshore-offshore gradient. Future studies on the mechanisms of zooplankton aggregation in this ecosystem will need to examine the behavior and distribution of individual species and their relationship to currents at small scales.

Of those groups identified as showing a significant nearshore-offshore pattern, 4 were addressed in previous studies in the same area, as were 4 that did not show an across-slope gradient in our study. Leis (1982) studied 6 crustacean species sampled between 0.2 and $3 \mathrm{~km}$ from the shoreline in an area overlapping with our southern study site. Hassett \& Boehlert (1999) also had a site overlapping our southern study site with samples taken 1.8, 9.3, and $28 \mathrm{~km}$ from the shoreline, with a focus on 4 species of copepods. Species of calanoid copepods (Undinula) and those from the family Pontellidae were categorized by both studies as 'nearshore associated' with higher abundances nearshore than offshore. In our study, pontellid copepods showed a significant pattern during only 1 of the 3 field efforts, and Undinula did not show an across-slope gradient in any period we studied. Leis (1982) further characterized Labidocera madurae, a species of euchaetid copepod, and a species of shrimp, Lucifer chacei, as showing a higher concentration nearshore, while neither showed a significant pattern in any of our sampling periods. Myctophid fish larvae were categorized in that study as an offshore group while they showed the opposite pattern in all 3 sampling periods of our study. Copepods from the calanoid family Calanidae were identified by Hassett \& Boehlert (1999) as being randomly distributed, as they were in all 3 of our sampling periods. A species of Acartia was randomly distributed in the observations of Leis (1982); however, it showed a strong nearshore-offshore gradient in our data. None of the other groups we found was discussed in the previous studies. The differences observed between the current and previous studies may have to do with taxonomic specificity of the studies. Previous studies typically identified only a fraction of the net sample and identified those individuals to species, while we took a broader look at the zooplankton samples, including all taxa at a coarser resolution. An even larger effect may be the temporal component of the sampling. Hassett \& Boehlert (1999) grouped their samples into 'night' and 'day' while Leis (1982) combined all samples, regardless of sampling time. We sampled from just before dusk through the night and were thus unable to look at daytime patterns. The extremely strong diel component observed here in all 3 sampling periods shows that samples taken just a few hours apart during the night can differ dramatically and thus pooling nighttime samples for analysis could alter the apparent across-slope distribution of abundance.

Acoustic, optical, and direct sampling were used to quantify zooplankton in this study. A comparison of the density estimates and size classes from all 3 methods showed similar results when the data from each were reduced to the same resolution. The greatest differences between techniques were not found in the integrated numbers that can be directly compared, but rather in the data each can uniquely provide. Net tows are the only sampling technique used that can provide direct measures of biomass, density, and species composition, although they can do so only over the entire depth range, and with the $333 \mu \mathrm{m}$ net we used, they can miss small animals. Both the optical (OPC) and acoustical (TAPS) approaches can provide depthspecific data of some measure of abundance by size but cannot provide information on animal identity. For both techniques, a description of the size distribution and body forms likely to be found are important for data interpretation. The OPC does not sample small particles (a problem corrected in the next generation of this instrument, the Laser OPC), is affected by the light transmittance characteristics of the zooplankton, and can mis-size animals when they are found at high densities (Herman 1988, 1992). TAPS is similarly affected by the acoustic scattering properties of zooplankton; for example, air inclusions and hard parts can increase acoustic scattering strength and must be accounted for (in this case, using net tow data; see summaries by Stanton et al. 1998a,b). Both of these indirect techniques rely on a relatively small sample volume, approximately $2.5 \mathrm{l}$, about 0.5 to $1.5 \mathrm{~m}$ away from the instrument in the case of the acoustics and in the case of the optics, a 0.11 volume passing through a $2 \times 25 \mathrm{~cm}$ rectangular channel in the instrument. This may bias both of these instruments against larger animals because of avoidance, a problem also likely to affect 
the net samples. However, the limited sampling depth over which the data must be integrated for the optical and acoustical methods ( $0.5 \mathrm{~m}$ in this case) to produce meaningful results from vertical profiles can significantly reduce the sample error.

The importance of this increased vertical resolution of the acoustic and optical samples relative to the net tows is shown clearly in Fig. 8. While the total mean density of zooplankton estimated from the acoustic and optical samples and their paired net tows are comparable, the biovolume of zooplankton as a function of depth changes 5 - to 10 -fold over vertical distances ranging from 1.0 to $2.5 \mathrm{~m}$. There was a minimum of 10 data points in each of the profile peaks. These increases in biovolume were observed in each of several replicate casts and simultaneously in both instruments. These types of 'thin layers' have been observed in zooplankton as well as phytoplankton in other habitats (Widder et al. 1999, Dekshenieks et al. 2001, McManus et al. 2003). Unfortunately, the net tows used (or any commonly used capture techniques) cannot sample these thin zooplankton aggregations to determine if their composition varies significantly between features or relative to the zooplankton background. However, it is likely that these intense zooplankton features are important to the foraging behavior of their predators, e.g. the micronekton in horizontally migrating layers (Leising 2001, Ignoffo et al. 2005).

Our data show that zooplankton biomass, density, and total abundance were substantially higher nearshore than offshore during nighttime hours when migrating micronekton species are feeding. This strong nighttime nearshore-offshore gradient was consistent among the 3 sampling approaches. However, it was not observed during the late daytime hours, suggesting that it is not simply the direct result of the island-mass effect. Our results support vertical migration coupled with horizontal movement due to swimming or advection as a potential mechanism for the observed pattern in zooplankton abundance as opposed to benthic emergence, which is not supported by the data. However, the variety of observed patterns in the vertically migrating taxa and the lack of a clear temporal pattern in the vertical distribution of zooplankton total density highlights the need for detailed species-specific behavioral observations to further our understanding of the drivers of zooplankton movement. However the observed pattern in zooplankton is formed, we can conclude from the results that if micronekton were to simply migrate vertically, they would be exposed to a lower density, abundance, and biomass of zooplankton potential prey than they experienced by their observed coupled vertical and horizontal movement. Zooplankton distribution patterns are thus consistent with horizontal migration by micro- nekton serving an adaptive feeding function. The micronektonic animals ( 2 to $10 \mathrm{~cm}$ in length) in these scattering layers travel distances of at least $11 \mathrm{~km}$ roundtrip each night (Benoit-Bird \& Au 2006), often against the prevailing currents (McManus et al. 2008), to access these increased nearshore zooplankton resources. This feeding advantage is likely an important evolutionary driver of the horizontal migrations observed in other micronektonic species in areas with high bottom relief (Sasaki 1914, Omori \& Ohta 1981, Bordes et al. 1999). However, while food may be an important reason to couple horizontal with vertical migration, the proximate cues that facilitate this nightly nearshore-offshore movement of micronekton remain uninvestigated.

Acknowledgements. This work was funded by the Office of Naval Research awards \# N00014-05-1-0035 (M.M.), \#N00014-05-1-0034 (K.B.B.) as well as National Science Foundation award \#IIS04-34078 (K.B.B. with Whitlow Au). We thank the Ko Olina Marina Harbormaster, M. Daily, B. McLaughlin, D. Merrit, C. Ostrander, D. Pence, J. Smith, G.. Steward, C. Stoebenau, O. Vetter, and C. Waluk for their assistance in the field and/or initial data processing. We thank W. Au, M. Baumgartner, T. Cowles, B. Mate, C. Miller, C. Wingard, and the Pacific Islands Fisheries Science Center for loaning pieces of equipment for this study. C. Miller built and calibrated the flowmeter, assisted with zooplankton identification, and provided helpful comments on an early draft of the manuscript. C. Wingard and M. Hitch provided logistical support. Captain J. Reich was critical to the success of the field operations. D. Van Holliday and C. Greenlaw assisted with equipment repair during field operations. C. Miller and C. Smith provided laboratory space. W. Au, M. Benfield, and D. Van Holliday were influential in the early discussions of this work.

\section{LITERATURE CITED}

Beaulieu SE, Mullin MM, Tang VT, Pyne SM, King AL, Twining BT (1999) Using an optical plankton counter to determine the size distribution of preserved zooplankton samples. J Plankton Res 21:1939-1956

> Benoit-Bird KJ, Au WWL (2001) Target strength measurements of animals from the Hawaiian mesopelagic boundary community. J Acoust Soc Am 110:812-819

Benoit-Bird KJ, Au WWL (2003) Echo strength and density structure of Hawaiin mesopelagic boundary community patches. J Acoustic Soc Am 114:1888-1897

> Benoit-Bird KJ, Au WWL (2006) Extreme diel horizontal migrations by a tropical nearshore resident micronekton community. Mar Ecol Prog Ser 319:1-14

$>$ Benoit-Bird KJ, Au WWL, Brainard RE, Lammers MO (2001) Diel horizontal migration of the Hawaiian mesopelagic boundary community observed acoustically. Mar Ecol Prog Ser 217:1-14

Blaxter JHS (1974) The role of light in the vertical migration of fish - a review. In: Evans GC, Bainbridge R, Rackham O (eds) Light as an ecological factor II: the 16th Symposium of the British Ecological Society. Blackwell Scientific Publications, Oxford

> Boehlert GW, Watson W, Sun LC (1992) Horizontal and vertical distributions of larval fishes around an isolated oceanic 
island in the tropical Pacific. Deep-Sea Res 39:439-466

Bordes F, Uiblein F, Castillo R, Barrera A and others (1999) Epi- and mesopelagic fishes, acoustic data, and SST images collected off Lanzarote, Fuerteventura and Gran Canaria, Canary Islands, during cruise 'La bocaina 04-97'. Inf Tec Inst Canario Cienc Mar 5:1-45

Brusca GJ (1973) Pelagic Amphipoda from the waters near Oahu, Hawaii, excluding the Family Scinidae. Pac Sci $27: 8-27$

Clarke GW (1970) Light conditions in the sea in relation to the diurnal vertical migrations of animals. In: Farquar GB (ed) Proceedings of an International Symposium on Biological Sound Scattering in the Ocean. Department of the Navy, Washington, DC, p 41-50

Clarke T (1978) Diel feeding patterns of 16 species of mesopelagic fishes from Hawaiian waters. Fish Bull (Wash DC) 76:495-513

Clarke TA (1980) Diets of fourteen species of vertically migrating mesopelagic fishes in Hawaiian waters. Fish Bull (Wash DC) 78:619-640

> Dekshenieks MM, Donaghay PL, Sullivan JM, Rines JEB, Osborn TR, Twardowski MS (2001) Temporal and spatial occurrence of phytoplankton thin layers in relation to physical processes. Mar Ecol Prog Ser 223:61-71

Doty MS, Oguri M (1956) The island mass effect. J Cons Int Explor Mer 22:33-37

Dower JF, Brodeur RD (2004) The role of biophysical coupling in concentrating marine organisms around shallow topographies. J Mar Syst 50:1-2

Enright JT (1977) Diurnal vertical migration: adaptive significance and timing. Limnol Oceanogr 22:856-886

Ferrari FD, Hayek LAC (1990) Monthly differences in distributions of sex and assymetry in a looking-glass copepod, Pleuromamma xiphias, off Hawaii. J Crustac Biol 10:114-127

Foote KG, Vestnes G, MacLennan DN, Simmonds EJ (1987) Calibration of acoustic instruments for fish density estimation: a practical guide. ICES Coop Res Rep 144. ICES, Copenhagen

Genin A (2004) Bio-physical coupling in the formation of zooplankton and fish aggregations over abrupt topographies. J Mar Syst 50:3-20

> George DG (1983) Interrelations between the vertical migration of Daphnia and chlorophyll a in two large limnetic enclosures. J Plankton Res 5:457-475

Gliwicz ZM (1986) Predation and the evolution of vertical migration in zooplankton. Nature 320:746-748

Hassett RP, Boehlert GW (1999) Spatial and temporal distributions of copepods to leeward and windward of Oahu, Hawaiian Archipelago. Mar Biol 134:571-584

Herman AW (1988) Simultaneous measurement of zooplankton and light attenuance with a new optical plankton counter. Cont Shelf Res 8:205-221

Herman AW (1992) Design and calibration of a new optical plankton counter capable of sizing small zooplankton. Deep-Sea Res I 39:395-415

Hirota J, Szyper JP (1076) Standing stocks of zooplankton size-classes and trophic levels in Kaneohe Bay, Oahu, Hawaiin Islands. Pac Sci 30:341-361

Hobson ES, Chess JR (1979) Trophic relationships among fishes and plankton in the lagoon Enewetak Atoll, Marshall Islands. Fish Bull 76:133-153

Holliday DV (1977) Extracting biophysical information from the acoustic signals of marine organisms. In: Anderson NR, Zahuranec BJ (eds) Oceanic sound scattering prediction. Plenum, New York, p 619-624

Holliday DV, Pieper RE (1995) Bioacoustical oceanography at high frequencies. ICES J Mar Sci 52:279-296
Hu VJH (1978) Relationships between vertical migration and diet in four species of euphausiids. Limnol Oceanogr 23:293-306

Ignoffo TR, Bollens SM, Bochdansky AB (2005) The effects of thin layers on the vertical distribution of the rotifer, Brachionus plicatilis. J Exp Mar Biol Ecol 316:167-181

> Kimmerer WJ (1984) Selective predation and its impact on prey of Sagitta enflata (Chaetognatha). Mar Ecol Prog Ser 15:55-62

- Lampert W (1989) The adaptive significance of diel vertical migration of zooplankton. Funct Ecol 3:21-27

> Leis JM (1982) Nearshore distributional gradients of larval fish and planktonic crustaceans in Hawaii. Mar Biol 72: 89-97

Leising AW (2001) Copepod foraging in patchy habitats and thin layers using a 2-D individual-based model. Mar Ecol Prog Ser 216:167-179

Longhurst AR (1981) Analysis of marine ecosystems. Academic Press, London

MacLennan DN, Simmonds EJ (1992) Fisheries acoustics. Chapman \& Hall, New York

McManus MM, Alldredge AL, Barnard AH, Boss E and others (2003) Characteristics, distribution, and persistence of thin layers over a 48 hour period. Mar Ecol Prog Ser 261:1-19

McManus MM, Benoit-Bird KJ, Woodson CB (2008) Behavior exceeds physical forcing in the diel horizontal migration of a midwater sound-scattering layer in Hawaiian waters. Mar Ecol Prog Ser 365:91-101

Medwin H, Clay C (1997) Fundamentals of acoustical oceanography. Academic Press, San Diego, CA

Ohman MD, Frost BW, Cohen EB (1983) Reverse diel vertical migration: an escape from invertebrate predators. Science 220:1404-1407

Omori M, Ohta S (1981) The use of underwater camera in studies of vertical distribution and swimming behaviour of a sergestid shrimp, Sergia lucens. J Plankton Res 3: 107-121

Reid SB (1994) Spatial structure of the mesopelagic fish community in the Hawaiian boundary region. $\mathrm{PhD}$ dissertation, University of Hawaii, Honolulu, HI

$>$ Reid SB, Hirota J, Young RE, Hallacher LE (1991) Mesopelagic-boundary community in Hawaii: micronekton at the interface between neritic and oceanic ecosystems. Mar Biol 109:427-440

Ringelberg J (1995) Changes in light intensity and diel vertical migration: a comparison of marine and freshwater environments. J Mar Biol Assoc UK 75:15-25

- Roe HSJ (1974) Observations on the diurnal vertical migrations of an oceanic animal community. Mar Biol 28:99-113

Sasaki M (1914) Observations on hotaru-ika, Watasenia scintillans. J Coll Agric Hokkaido Univ 6:75-107

Stanton TK, Chu D, Wiebe PH (1998a) Sound scattering by several zooplankton groups: II. Scattering models. J Acoust Soc Am 103:236-253

Stanton TK, Chu D, Wiebe PH, Martin LV, Eastwood RL (1998b) Sound scattering by several zooplankton groups: I. Experimental determination of dominant scattering mechanisms. J Acoust Soc Am 103:225-235

> Stich HB, Lampert W (1981) Predator evasion as an explanation of diurnal vertical migration by zooplankton. Nature 293:396-398

Szyper JP, Hirota J, Caperaon J, Ziemann DA (1976) Nutrient regeneration by the larger net zooplankton in the southern basin of Kaneohe Bay, Oahu, Hawaiin Islands. Pac Sci 30:363-372

- Widder EA, Johnsen S, Bernstein SA, Case JF, Neilson DJ (1999) Thin layers of bioluminescent copepods found at density discontinuities in the water column. Mar Biol 134: 429-437

Submitted: February 6, 2008; Accepted: May 14, 2008

Proofs received from author(s): September 4, 2008 